\title{
Assessment of knowledge, attitude, practice and perceived barriers of breastfeeding among women attending antenatal care follow up at Nekemte Specialized Hospital, Nekemte, Ethiopia
}

\author{
Dame Fikadu Keneni \\ Department of Emergency Medicine, Jimma University, Jimma, Ethiopia
}

\begin{abstract}
Introduction: Early initiation and exclusive breastfeeding are encouraged for a number of reasons. A child should receive breast milk with other complementary foods starting from the age of 6 months to 24 months. However, conditions related to the mother and infant contributed to a delay in initiation of breastfeeding and duration of breastfeeding practice.

Material and methods: A cross-sectional study design was employed with a direct face-to-face interview of the subjects. Data were coded, validated and analyzed using SPSS version 23.0 and finally presented in tables and figures.

Results: All women who were interviewed know about early breastfeeding and those who had a previous maternal experience have exclusively breastfed their infants for some time. $61.05 \%$ of mothers initiated breastfeeding within $1 \mathrm{~h}$ after delivery. $65.66 \%, 59.64 \%, 51.58 \%$ of mothers know, believe and practiced exclusive breastfeeding for full 6 months respectively and $55.42 \%$ and $57.89 \%$ of mothers know and have practiced breastfeeding their child more than eight times a day respectively. The most common perceived barriers to breastfeeding are being too busy to breastfeed and lack of support to the mother. Age of the mother $>18$ years, educational level of $>8^{\text {th }}$ grade and previous maternal experience, improve their knowledge about early initiation of breastfeeding, importance of colostrum feeding and frequency of complementary feeding.

Conclusions: Knowledge about time of initiation of breastfeeding and attitude are good but the practice lags behind and the knowledge, attitude and practice of the frequency of breastfeeding is not optimal.

Key words: pre-lacteal feeds, early breastfeeding, weaning, morbidity, mortality, antenatal care.
\end{abstract}




\section{Introduction}

Breastfeeding (BF) is the normal way of giving infants the needed nutrients for proper growth and is the ideal and superior food for infants for the first 2 years of life and the sole source of nutrition for the first 6 months. A wide range of socio-economic and psychological benefits of BF for mother, child and family are well known and documented in many perspectives $[1,2]$. Furthermore, it is well known that these benefits can be either immediate or long term $[3,4]$. To promote $\mathrm{BF}$ and ensure that adequate counseling and support are provided to initiate and maintain BF practices, UNICEF and WHO started the Baby Friendly Initiative (BFI) in 1991 and required 10 steps for hospital accreditation as baby friendly, and in 2017 there are 152 baby friendly hospitals [2].

Breastfeeding is the only recommended method for feeding infants during approximately the first 6 months of life. Colostrum, high-protein, low-fat fluid is produced in small amounts during the first postpartum days. It has some nutritional values, but primarily has immunologic and maturational properties. Exclusive BF during the first 6 months of life and then continuation while adding complementary feeding up to 2 years was and is still recommended by WHO, UNICEF and American Academy of Pediatrics (AAP 2012) [1, 4]. It is supported in many recent systematic reviews for healthy growth and development and proper digestion of the infant [5] in addition to protection from respiratory infections and diarrheal disease and severity of diarrhea, respiratory illnesses, otitis media, bacteremia, bacterial meningitis and necrotizing enterocolitis $[6,7]$. Also it is used to treat obesity and certain non-communicable diseases including asthma, diabetes and heart diseases later in life [8]. Moreover, it helps with the improvement of academic achievement [6] and reduces the risk of childhood leukemia [7]. Also, it fosters the process of attachment between mother and baby leading to a sense of well-being and security. Longer breastfeeding duration improves bone strength and decreases the risk of breast and ovarian cancer [9], postpartum hemorrhage and some cardiovascular diseases for the mother [9].

Initiating breastfeeding in the first hour of life decreases the risk of neonatal death by $20 \%$. Society also benefits by decreasing medical costs such as sick care visits, prescriptions and hospitalizations [10]. Recent analyses indicate that suboptimal breastfeeding practices in terms of initiation, exclusivity and duration contribute to over 800,000 deaths $(11.6 \%)$ in children under 5 years of age. Accordingly, following the international organizations' recommendations would decrease children morbidity and mortality [11].

Referring to the perceived barriers of breastfeeding, it was reported that working, low income, pushing formula into hospital and heavy formula advertisements can limit the breastfeeding practices [12] in addition to lack of information, fear of pain, misconceptions, worries about breastfeeding in public, negative postpartum hospital experiences and lack of support after going home [12]. Others like insufficient milk supply, being too busy to breastfeed, change in breast shape and availability of housekeepers acted as barriers among some women [13].

Breastfeeding is feasible if women are well informed and supported [13]. These could be best achieved if women are educated and informed about BF specially starting from the antenatal care (ANC) follow up. Additionally, breastfeeding is a natural practice and a learned behavior [14]. Although it is a natural practice, still there are many factors negatively affecting women's attitudes toward it. Some mothers find it difficult to adhere to early breastfeeding (EBF) for 6 months despite the increased rate of initiation [15]. Also, mixed feeding was the common way of feeding. Additionally, reasons for discontinuing breastfeeding were individualized and include sickness of the mother or the baby, use of contraception or taking drugs [8]. At the same time, some factors remain inconclusive and not well clarified in detail so additional examination is of concern $[12,15]$.

No other factor is more important for successful breastfeeding than the mother's happy relaxed state of mind [ 1 , 16]. Many mothers do not feel comfortable when trying to nurse in an open world, or even with another person in the room. Several reflexes of behavior patterns that facilitate breastfeeding are present at birth. These include the rooting, sucking and swallowing and satiety reflexes $[16,17]$. These reflexes are often absent or erratic during periods of pain, fatigue or emotional distress. This is thought to be a common cause of milk retention in women, who are unsuccessful in breastfeeding $[4,16]$.

Nursing mothers should not take drugs unless they are absolutely necessary $[3,17]$. She should be discouraged from smoking cigarettes and drinking alcoholic beverages. Infants whose mothers were sedated during labor usually suck at lower rates and pressures and also consume less milk than infants of non-sedated mothers $[3,17]$. Acute maternal infection may contraindicate breastfeeding. Unless the condition of either the mother or the infant necessitates, there is no need to stop nursing [16]. When the infant is unaffected, the breast may be emptied and the milk may be given to the infant by bottle or cup $[3,16,17]$.

ANC, a program designed for pregnant women during the prenatal period for better maternal, fetal and infant outcome, is the health care given to a pregnant woman so as to ensure the birth of a healthy baby with a minimal health risk to the mother [9].

Thus, it is a goal oriented with interventions/intervention-oriented goal to achieve the medical and psychological needs of pregnant women, which have proven values. Its strategies target pregnant women to help them maintain normal pregnancies and delivery. Under this strategy women are counseled on important issues including child nutrition and also can discuss any issues concerning the pregnancy and future child care $[9,13]$.

\section{Material and methods}

A cross-sectional study design was employed to assess breastfeeding knowledge, attitude, practice and perceived barriers among 166 women attending ANC follow up at 
Nekemte Specialized Hospital, Nekemte, southwest Ethiopia on Dec 15-30, 2019.

All volunteer women seen at ANC follow up clinic at the study area during the study period were interviewed with structured questionnaire by a direct face-to-face interview. The questionnaire format was prepared in such a way that it included the identification and general information on socio-demographic and economic characteristics, knowledge, attitude and practice of breastfeeding. Data were collected by face-to-face interview by data collectors and then coded, validated and analyzed using SPSS PC + software package version 23.0 and finally presented by using tables and figures.

Table I. Frequency distribution of socio-demographic characteristics of women attending ANC follow up clinic of Nekemte Specialized Hospital in Dec 2019

\begin{tabular}{|c|c|c|c|}
\hline Variables & Characteristics & $N$ & $\%$ \\
\hline \multirow[t]{3}{*}{ Age of mothers } & $<20$ & 5 & 3.01 \\
\hline & $20-34$ & 150 & 90.36 \\
\hline & $35-49$ & 11 & 6.63 \\
\hline \multirow[t]{3}{*}{ Marital status } & Single & 4 & 2.41 \\
\hline & Married & 157 & 94.58 \\
\hline & Divorced & 5 & 3.01 \\
\hline \multirow[t]{5}{*}{ Religion } & Orthodox & 43 & 25.90 \\
\hline & Protestant & 87 & 52.41 \\
\hline & Muslim & 16 & 9.64 \\
\hline & Catholic & 12 & 7.23 \\
\hline & Other ${ }^{\#}$ & 8 & 4.82 \\
\hline \multirow[t]{4}{*}{ Ethnicity } & Oromo & 135 & 81.33 \\
\hline & Amhara & 15 & 9.04 \\
\hline & Gurage & 9 & 5.42 \\
\hline & Other* & 7 & 4.22 \\
\hline \multirow[t]{5}{*}{ Occupational status } & Housewife & 56 & 33.73 \\
\hline & $\begin{array}{l}\text { Government } \\
\text { employee }\end{array}$ & 40 & 24.10 \\
\hline & Merchant & 37 & 22.29 \\
\hline & Daily laborer & 25 & 15.06 \\
\hline & Other** & 8 & 4.82 \\
\hline \multirow[t]{4}{*}{ Educational level } & $\begin{array}{l}\text { No formal } \\
\text { schooling }\end{array}$ & 6 & 3.61 \\
\hline & 1-8 grade & 44 & 26.51 \\
\hline & $9-12$ grade & 69 & 41.57 \\
\hline & $\begin{array}{l}\text { College or } \\
\text { university }\end{array}$ & 47 & 28.31 \\
\hline \multirow[t]{4}{*}{ Access to information } & Radio & 64 & 38.55 \\
\hline & TV & 116 & 69.88 \\
\hline & Internet & 87 & 52.41 \\
\hline & Other $* * *$ & 23 & 13.86 \\
\hline
\end{tabular}

"Wakefata, no religion, ${ }^{\star}$ Tigre, Dawuro, Keffa, ${ }^{\star *}$ farmer, servant, private sector employee, ${ }^{* *}$ newspaper, from other people.
Age, sex, marital status, ethnicity, religion, educational status, occupation and income were used as independent variables, whereas knowledge, attitude and practice were the dependent variables.

\section{Operational definitions}

Pre-lacteal Feeds - feeding which started before the start of breast milk. Exclusive Breastfeeding - breastfeeding without any supplementary feeding. Medications and drugs excluded. Infant - a child younger than 1 year. Weaning the process during which breast milk is replaced by other nutrition/foods (solid, semisolid or liquid). Nutrient - any organic and inorganic components and elements contained in foods and utilized in normal metabolism of the body. Morbidity - the rate of disease occurrence or the proportion of diseased persons in a given population in a year. Mortality - the rate of death or the proportion of persons who have died in a given population in a year. ANC - is the health care given to a pregnant woman so as to ensure the birth of a healthy baby with a minimal health risk to the mother. Maternal experience - women who have not given birth at all or gave birth to alive child or a child who subsequently thrives.

\section{Ethical consideration}

The study was confirmed and approved by the Jimma University Student Research Program, Community Based Education office and informed verbal consent was ob- tained from each member of the study population and all personal information of the study subjects and results are processed in high exclusiveness and confidentiality.

\section{Results}

\section{Socio-demographic characteristics of the participants}

During the study period, a total of 166 women who visited the ANC clinic of Nekemte Hospital were interviewed to assess the knowledge, attitude, practice and perceived barriers of breastfeeding among women. Majority, namely 150 (90.36\%) women were in the age interval $20-34$ years. Regarding their educational background, 6 (3.61\%) were found to be with no formal schooling, out of the literate groups, $44(26.51 \%)$ are educated up to grade 8 and majority, 69 (41.57\%) were with the educational level of 9-12 grades and $47(28.31 \%)$ are educated up to college or university. Concerning their marital status, 157 (94.58\%) of them were married. Among these women, 56 (33.73\%) were housewives, $40(24.10 \%)$ were government employee and 37 (22.29\%) merchants (Table I).

\section{Maternal experience}

Among women who visited the ANC follow up clinic, 71 (42.77\%) had no maternal experience and 95 (57.23\%) had a previous experience of maternity. From these mothers, 71 (74.74\%) had at least one ANC follow up in the previous pregnancy(ies) and $52(73.24 \%)$ of them were counseled on breastfeeding at any time period during the ANC follow up. The characteristics of maternal experience are shown in Table II. 
Table II. Frequency distribution of women with a previous maternal experience among women attending ANC follow up of Nekemte Specialized Hospital in Dec 2019

\begin{tabular}{|l|c|c|c|c|}
\hline Characteristics & \multicolumn{3}{|c|}{ Previous ANC } & \multicolumn{2}{|c|}{ Counseled about BF* } \\
\hline Yes & 71 & 74.74 & 52 & 73.24 \\
\hline No & 24 & 25.26 & 19 & 26.76 \\
\hline Total & 95 & 100.00 & 71 & 100.00 \\
\hline
\end{tabular}

*For women who had previous ANC follow up.

Table III. Frequency distribution on knowledge about breastfeeding among women attending ANC follow up of Nekemte Specialized Hospital in Dec 2019

\begin{tabular}{|c|c|c|c|}
\hline Variables & Knowledge & $N$ & $\%$ \\
\hline \multirow[t]{4}{*}{ Time of initiation of BF } & Within $1 \mathrm{~h}$ of birth & 97 & 58.43 \\
\hline & $1-2 \mathrm{~h}$ & 51 & 30.72 \\
\hline & $2-24 \mathrm{~h}$ & 12 & 7.23 \\
\hline & After $24 \mathrm{~h}$ of birth & 6 & 3.61 \\
\hline \multirow[t]{2}{*}{ Colostrum feeding is good } & Yes & 129 & 77.71 \\
\hline & No & 37 & 22.29 \\
\hline \multirow[t]{5}{*}{ Duration of EBF } & $<3$ months & 21 & 12.65 \\
\hline & $3-5$ months & 36 & 21.69 \\
\hline & 6 months & 96 & 57.83 \\
\hline & $6-8$ months & 11 & 6.63 \\
\hline & $>8$ months & 2 & 1.20 \\
\hline \multirow[t]{4}{*}{ Frequency of breastfeeding } & On demand & 61 & 36.75 \\
\hline & 4-8 times & 31 & 18.67 \\
\hline & $8-12$ times & 45 & 27.11 \\
\hline & $>12$ times & 29 & 17.47 \\
\hline \multirow[t]{5}{*}{ Total duration of BF } & $<1$ year & 4 & 2.41 \\
\hline & $1-2$ years & 39 & 23.49 \\
\hline & 2 years & 78 & 46.99 \\
\hline & $2-3$ years & 41 & 24.70 \\
\hline & $>3$ years & 4 & 2.41 \\
\hline
\end{tabular}

\section{Knowledge of women about BF}

From the interviewed women, $155(93.37 \%)$ know that $\mathrm{EBF}$ is important and of these, most, 96 (57.83\%), know that it should be for 6 months. Of the total interviewed women, 57 (34.34\%) think that EBF for full 6 months is too long and disadvantageous for the infant and 13 (7.834\%) think it is too short and affects the infant's growth, weight and health.

From the women who know about EBF (155 women), most, 101 (65.16\%) think that complementary feeding should be started with water, followed by milk, gruel and others like butter, combination of the above - 31 (20.00\%), $14(9.03 \%)$ and $9(5.81 \%)$, respectively. And also, with regard to the frequency of giving complementary feeding, 33 (19.88\%), 97 (58.43\%) and $36(21.69 \%)$ think that it should be given $<3$ times per day, 3 to 5 times and $>5$ times per day, respectively. The other characteristics of knowledge about $\mathrm{BF}$ of these women are shown in Table III.

\section{Attitude towards breastfeeding}

The attitude of participants towards breastfeeding is shown in Table IV. Generally the attitude among women towards $\mathrm{BF}$ is that all of the women believe that there is a difference in terms of growth and development between a breastfed child and non-breastfed child and most 98 (59.04\%) agreed on the initiation of breastfeeding within $1 \mathrm{~h}$ of birth while $54(32.53 \%)$ believe it should be initiated after $1 \mathrm{~h}$ to $2 \mathrm{~h}$ of birth. And also, all of the women believe that a child should be weaned gradually and not suddenly.

\section{Practices of breastfeeding}

Table V shows breastfeeding practice of women who had a previous maternal experience. Among all of the interviewed women, 95 (57.23\%) have maternal experience and all of them have breastfed their child previously. Fifty-eight $(61.05 \%)$ of the mothers had initiated breastfeeding within $1 \mathrm{~h}$ of birth while 37 (38.95\%) started after $1 \mathrm{~h}$. 
Table IV. Number and percentage distribution of attitude towards breastfeeding of women attending ANC follow up of Nekemte Specialized Hospital in Dec 2019

\begin{tabular}{|c|c|c|c|c|}
\hline Variables & \multicolumn{2}{|c|}{ Attitude } & $N$ & $\%$ \\
\hline \multirow[t]{5}{*}{ Initiation } & \multicolumn{2}{|c|}{ Within $1 \mathrm{~h}$} & 98 & 59.04 \\
\hline & \multicolumn{2}{|c|}{$1-2 \mathrm{~h}$} & 54 & 32.53 \\
\hline & \multicolumn{2}{|c|}{$2-24 \mathrm{~h}$} & 9 & 5.42 \\
\hline & \multicolumn{2}{|c|}{$24-72 \mathrm{~h}$} & 3 & 1.81 \\
\hline & \multicolumn{2}{|c|}{$>3$ days } & 2 & 1.20 \\
\hline \multirow[t]{2}{*}{ Pre-lacteal feeds } & \multicolumn{2}{|c|}{ Yes } & 11 & 6.63 \\
\hline & \multicolumn{2}{|c|}{ No } & 155 & 93.37 \\
\hline \multirow[t]{5}{*}{ Feeding for first 6 months } & \multicolumn{2}{|c|}{ Only BF } & 99 & 59.64 \\
\hline & \multicolumn{2}{|c|}{ BF plus cow's milk } & 27 & 16.27 \\
\hline & \multicolumn{2}{|c|}{ BF plus water } & 35 & 21.08 \\
\hline & \multicolumn{2}{|c|}{ Cow's milk only } & 0 & 0.00 \\
\hline & \multicolumn{2}{|c|}{ Other* } & 5 & 3.01 \\
\hline \multirow[t]{3}{*}{ When to BF } & \multicolumn{2}{|c|}{ By schedule } & 101 & 60.84 \\
\hline & \multicolumn{2}{|c|}{ When mother is free } & 4 & 2.41 \\
\hline & \multicolumn{2}{|c|}{ When the baby seeks } & 61 & 36.75 \\
\hline \multirow[t]{7}{*}{$\mathrm{BF}$ for 2 years } & \multicolumn{2}{|c|}{ Enough } & 97 & 58.43 \\
\hline & \multicolumn{2}{|c|}{ Not enough } & 35 & 21.08 \\
\hline & \multicolumn{2}{|c|}{ Excessive } & 34 & 20.48 \\
\hline & \multirow{4}{*}{$\begin{array}{l}\text { If not enough or } \\
\text { Excessive }\end{array}$} & $<1$ year & 6 & 3.61 \\
\hline & & $1-2$ years & 28 & 16.87 \\
\hline & & $2-3$ years & 29 & 17.47 \\
\hline & & $>3$ years & 6 & 3.61 \\
\hline \multirow[t]{2}{*}{ Weaning } & \multicolumn{2}{|c|}{ Gradual } & 166 & 100.00 \\
\hline & \multicolumn{2}{|c|}{ Sudden } & 0 & 0.00 \\
\hline
\end{tabular}

${ }^{*}$ Formula milk, breast milk with formula.

Table V. Breast feeding practice of women with a previous maternal experience among women attending ANC follow up of Nekemte Specialized Hospital in Dec 2019

\begin{tabular}{|c|c|c|c|}
\hline Variables & Practice & $N$ & $\%$ \\
\hline \multirow[t]{4}{*}{ Initiation } & Within $1 \mathrm{~h}$ & 58 & 61.05 \\
\hline & $1-2 \mathrm{~h}$ & 25 & 26.32 \\
\hline & $2-24 \mathrm{~h}$ & 10 & 10.53 \\
\hline & After $24 \mathrm{~h}$ & 2 & 2.11 \\
\hline \multirow[t]{4}{*}{ Duration of EBF } & $<3$ months & 5 & 5.26 \\
\hline & 4-6 months & 38 & 40.00 \\
\hline & 6 months & 49 & 51.58 \\
\hline & $>6$ months & 3 & 3.16 \\
\hline \multirow{4}{*}{$\begin{array}{l}\text { Complementary feeding is given } \\
\text { by }\end{array}$} & Bottle & 32 & 33.68 \\
\hline & Spoon & 22 & 23.16 \\
\hline & Hand & 4 & 4.21 \\
\hline & Cup & 37 & 38.95 \\
\hline \multirow[t]{4}{*}{ Total duration of BF } & $<1$ year & 10 & 10.53 \\
\hline & $1-2$ years & 37 & 38.95 \\
\hline & 2 years & 39 & 41.05 \\
\hline & $>2$ years & 9 & 9.47 \\
\hline
\end{tabular}




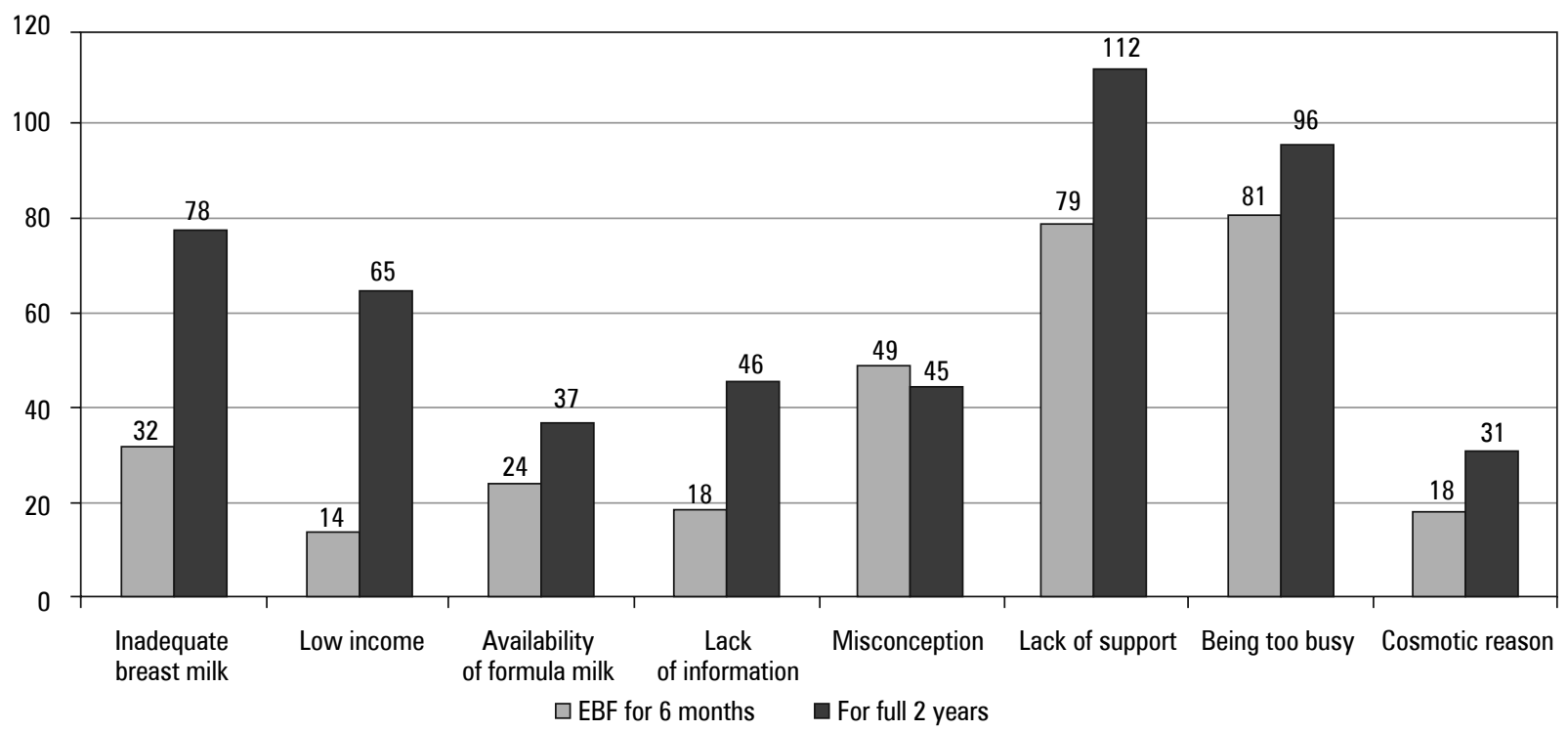

Figure 1. Perceived barriers of breast feeding among women attending ANC follow up of Nekemte Specialized Hospital in Dec, 2019

All of them have exclusively breastfed their child for some time and most, 49 (51.58\%), for the whole 6 months. Some mothers have also given pre-lacteal feeding to their neonates $(n=7,7.37 \%)$, most of them $(n=5,71.43 \%)$ gave water as pre-lacteal feeding followed by formula milk and cow's milk ( $n=1,14.29 \%$ each). All of the mothers weaned their child gradually. Among mothers who have breastfed, majority had said they feed more than eight times a day 55 (57.89\%) and $40(42.11 \%)$ feed less than eight times a day. Importance of breast milk explained by medical or paramedical staff to participants who had a maternal experience and had ANC follow up in previous pregnancy(ies) in this study was 52 (73.24\%) (Table II).

\section{Perceived barrier to breast}

Figure 1 shows perceived barriers to EBF for full 6 months and the perceived barriers to breast feed for a total duration of for 2 years. From the interviewed 166 women, most believe that the barriers to both EBF and total duration of $\mathrm{BF}$ are being too busy due to the job (81, 96 respectively) and lack of support from the family $(79,112$ respectively) and some of the women also mention lack of information (18, 46 respectively) and misconceptions about BF $(49,45$ respectively) as a reason for the barriers and all of these women believe that the reason for the lack of information and misconception is low access to information and misinterpretation of the given information.

\section{Discussion}

This study shows that among women who have had a maternal experience, all mothers have exclusively breastfed their infants and $51.58 \%$ of them breastfed for 6 months, which is lower than in a study conducted in Abha city, Saudi Arabia, which was 55.3\% [18], Calabar, Nigeria, which was $80 \%$ [19] and Bedele town in Ethiopia where it is was $87.3 \%$ [20]. However this rate was higher than in a study done in Nigeria where it was $31 \%$ [21] and still higher than the global figure (38\%) [7] and comparable to Ethiopia's figure (52\%) [5].

In this study, $61.05 \%$ of the mothers initiated breastfeeding within the first hour after delivery and $97.90 \%$ has already started within $24 \mathrm{~h}$ of delivery, which is higher than in a study conducted in Mizan Aman town, Ethiopia, which was $73.3 \%$ [22] and the national value (69\%) [5] and comparable to studies done in Saudi Arabia, where they have reported breastfeeding initiation within $48 \mathrm{~h}$ ranging between 92 and $100 \%$ [22-25]. And 7.37\% of the women have given pre-lacteal feeding to their neonates, which is significantly lower than the national level (37\%). Among these water (71.43\%), cow's milk (14.24\%) and formula milk (14.24\%) are the commonly used pre-lacteal feeding and none of the respondents in the study area gave non-milk liquids. Whereas, at the national level, $37 \%$ give pre-lacteal feeding; water (19\%), milk (14) and non-milk liquids and juice (4\%) [5].

Knowledge of respondents on importance of colostrum in this study is shown in $77.71 \%$, which is comparable to a study done in Jordan (79.67\%) [26], but higher than in a study conducted in Mizan Aman town, Ethiopia, which was $60.2 \%$ [22]. Maternal knowledge of frequent BF $>8$ times per day is shown by $44.58 \%$ of women. On demand feeding is $36.75 \%$ in this area which is lower than a finding of a study done in island of Abu Dhabi, United Arab Emirates (53.1\%) [27] and the national level (46\%) [5]. 59.64\% of the respondents have a positive attitude towards EBF for total of 6 months. The finding is lower than in reports done in Mizan Aman town, Ethiopia, which is $89.5 \%$ [22].

As shown on Table VI, there are some correlations between the socio-demographic background like women's age, educational level, occupation and previous maternal experience and their knowledge about breastfeeding. The educational level and previous maternal experience positively affect some aspects of women's knowledge and attitude towards breastfeeding. This finding shows that the age of the mother (being $>18$ years) improves their knowledge about early initiation of $\mathrm{BF}$, importance of co- 
Table VI. Association of demographic factors with the knowledge of BF among women attending ANC follow up of Nekemte Specialized Hospital in Dec 2019

\begin{tabular}{|c|c|c|c|c|c|c|}
\hline Knowledge & \multicolumn{2}{|c|}{ Educated $>8^{\text {th }}$ grade } & \multicolumn{2}{|c|}{ Has previous BF experience } & \multicolumn{2}{|c|}{ Age $>18$} \\
\hline \multirow{2}{*}{$\begin{array}{l}\text { Initiation of BF } \\
\text { within } 1 \mathrm{~h}\end{array}$} & $\chi^{2}=1.948$ & \multirow{2}{*}{$\begin{array}{l}\text { Has no } \\
\text { association }\end{array}$} & $\chi^{2}=0.302$ & \multirow{2}{*}{$\begin{array}{l}\text { Has no } \\
\text { association }\end{array}$} & $\chi^{2}=5.19$ & \multirow[t]{2}{*}{ Has association } \\
\hline & $p=0.25$ & & $p=0.75$ & & $p=0.025$ & \\
\hline \multirow{2}{*}{$\begin{array}{l}\text { No pre-lacteal feed } \\
\text { given }\end{array}$} & $\chi^{2}=8.419$ & \multirow[t]{2}{*}{ Has association } & $\chi^{2}=0.302$ & \multirow{2}{*}{$\begin{array}{l}\text { Has no } \\
\text { association }\end{array}$} & $\chi^{2}=2.82$ & \multirow{2}{*}{$\begin{array}{c}\text { Has no } \\
\text { association }\end{array}$} \\
\hline & $p=0.005$ & & $p=0.75$ & & $p=0.10$ & \\
\hline \multirow[t]{2}{*}{ EBF for 6 months } & $\chi^{2}=4.898$ & \multirow[t]{2}{*}{ Has association } & $\chi^{2}=28.05$ & \multirow[t]{2}{*}{ Has association } & $\chi^{2}=4.52$ & \multirow{2}{*}{$\begin{array}{c}\text { Has no } \\
\text { association }\end{array}$} \\
\hline & $p=0.01$ & & $p=0.001$ & & $p=0.05$ & \\
\hline \multirow{2}{*}{$\begin{array}{l}\text { Frequent BF } \\
>8 \text { times a day }\end{array}$} & $\chi^{2}=1.04$ & \multirow{2}{*}{$\begin{array}{c}\text { Has no } \\
\text { association }\end{array}$} & $\chi^{2}=12.88$ & \multirow[t]{2}{*}{ Has association } & $\chi^{2}=3.97$ & \multirow{2}{*}{$\begin{array}{c}\text { Has no } \\
\text { association }\end{array}$} \\
\hline & $p=0.50$ & & $p=0.001$ & & $p=0.05$ & \\
\hline \multirow[t]{2}{*}{ Colostrum feeding } & $\chi^{2}=1.187$ & \multirow{2}{*}{$\begin{array}{l}\text { Has no } \\
\text { association }\end{array}$} & $\chi^{2}=0.227$ & \multirow{2}{*}{$\begin{array}{c}\text { Has no } \\
\text { association }\end{array}$} & $\chi^{2}=12.45$ & \multirow[t]{2}{*}{ Has association } \\
\hline & $p=0.50$ & & $p=0.75$ & & $p=0.001$ & \\
\hline \multirow{2}{*}{$\begin{array}{l}\text { BF for a total } \\
\text { of } 2 \text { years }\end{array}$} & $\chi^{2}=0.049$ & \multirow{2}{*}{$\begin{array}{c}\text { Has no } \\
\text { association }\end{array}$} & $\chi^{2}=10.39$ & \multirow[t]{2}{*}{ Has association } & $\chi^{2}=0.189$ & \multirow{2}{*}{$\begin{array}{l}\text { Has no } \\
\text { association }\end{array}$} \\
\hline & $p=0.9$ & & $p=0.005$ & & $p=0.75$ & \\
\hline \multirow{2}{*}{$\begin{array}{l}\text { Frequent } \\
\text { complementary } \\
\text { feeding } \\
>3 \text { times a day }\end{array}$} & $\chi^{2}=26.839$ & \multirow{2}{*}{$\begin{array}{c}\text { Has no } \\
\text { association }\end{array}$} & $\chi^{2}=2.23$ & \multirow{2}{*}{$\begin{array}{c}\text { Has no } \\
\text { association }\end{array}$} & $\chi^{2}=5.272$ & \multirow[t]{2}{*}{ Has association } \\
\hline & $p=0.001$ & & $p=0.25$ & & $p=0.025$ & \\
\hline
\end{tabular}

lostrum feeding and frequency of complementary feeding (the results of $p$-value from their $\chi^{2}$ test are all $<0.05$ ). The educational level of grade $>8$ significantly influences the knowledge of women on early initiation of BF of $<$ $1 \mathrm{~h}$ and importance of exclusive breastfeeding for a total of 6 months (the results of $p$-value from their $\chi^{2}$ test are all $<0.05)$. Also, previous maternal experience improves women's knowledge about early initiation of BF, importance of exclusive breastfeeding for full 6 months, value of frequent of $\mathrm{BF}>8$ times a day and $\mathrm{BF}$ for a total of 2 years (the results of $p$-value from their chi square test are all $<0.05)$. A study done in Lahore, Pakistan concluded that there is an association between education and BF initiation within $1 \mathrm{~h}$ of delivery $\left(\chi^{2}=19.885\right.$ and $\left.p=0.001\right)$, EBF practice $\left(\chi^{2}=23.156\right.$ and $\left.p<0.001\right)$ and there is no association between employment and EBF practice $\left(\chi^{2}=\right.$ 3.328 and $p=0.68)$ or early initiation of BF within $1 \mathrm{~h}$ $\left(\chi^{2}=1.021\right.$ and $\left.p=0.312\right)[28]$.

\section{Conclusion and recommendation}

From the analysis of the results obtained it can be concluded that knowledge about and attitude towards appropriate breastfeeding are good but the practice is not comparable with the knowledge.

Most mothers with a previous maternal experience had ANC follow up but there are some mothers that were not counseled about BF despite having ANC follow up.

It was observed that the knowledge attitude and practice of exclusive breastfeeding was higher and also the majority initiates BF within $1 \mathrm{~h}$ and does it for a total of 6 months. Although knowledge about and attitude towards breastfeeding frequently of 8-12 times per day is good, the practice lags behind. Knowledge, attitude and practice of pre-lacteal feeding is that the women know it is harmful or not important but some still do it.

The most perceived barrier to breastfeeding practice in terms of EBF for 6 months and BF for total 2 years are being too busy to breastfeed and lack of support from the family and work place and also some belief that there is still some lack of information about BF.

In general, the following recommendations are put forward to improve the patterns and behavior of breastfeeding among study groups:

1. Women should frequently be educated about importance of the total duration of exclusive breastfeeding.

2. Health care professionals working at ANC follow up clinic should counsel on BF and emphasize EBF and frequency of BF.

3. Pre-lacteal feeding practice should be discouraged.

4. Health information about every aspect of BF should be emphasized through different BF promoting programs, by media, health extension workers and health care providers at every contact with women of child bearing age.

5. These findings should be used by health professionals when attempting to help mothers overcome breastfeeding barriers and to health officials attempting to devise targeted breastfeeding interventions on those issues.

6. Intervention programs by government and NGOs can be effective in promoting support for breastfeeding if it is started from the level of ANC follow up.

7. Such findings, if addressed comprehensively by health care providers and decision-makers, will lead to improvement of child health in the study community.

This study can be a pilot study in the Nekemte town and a more comprehensive study should be done in the town including both pregnant women before delivery and those who are currently breastfeeding. 


\section{Conflict of interest}

The authors declare no conflict of interest.

\section{References}

1. World Health Organization. Infant and young child feeding. Model Chapter for textbooks for medical students and allied health professionals. France; WHO, 2009. Access: August 23, 2016. Available from: http://apps.who.int/iris/bitstre am/10665/44117/1/9789241597494_eng.pdf?ua=1

2. UNICEF. The Baby Friendly Hospital Initiative. Retrieved from http://www.unicef.org. Accessed: 31 October 2015.

3. World Health Organization. Nutrition. WHA65/6. Comprehensive implementation plan on maternal, infant and young child nutrition. Access: June 28, 2014. Available from: http://www.who.int/ nutrition/topics/wha_65_6/en/9.

4. UNICEF. Progress for Children. A World Fit for Children Statistical Review. New York, USA: UNICEF, 2007. Access: august 23, 2016. Available from: http://www.unicef.org/ publications/files/ Progress_for_Children_No_6_revised.pdf

5. Kramer MS, Kukuma R. Optimal duration of exclusive breastfeeding. Cochrane Database Syst Rev 2012; 15: CD003517.

6. Oddy WH, Zubrick SR, Malacova E. Breastfeeding duration and achievement at 10 years. Pediatrics 2011; 127: E137-45.

7. Amitay EL, Boker LK. Breastfeeding and childhood leukemia incidence: a meta-analysis and systematic review. JAMA Pediatrics 2015; 169: 515-612.

8. Horta BL, Victora CG. Long-term effects of breastfeeding: a systematic review. World Health Organization. Geneva 2013

9. Hailemariam S, Dereje N. JUSH Obs Management guideline on selected obstetric topics, 1st ed., Focused Antenatal Care, Jimma (Ethiopia), Jan 2010; P. 78-84

10. Debes AK, Kohli A, Walker N, Edmond K, Mullany LC. Initiation of breastfeeding and neonatal mortality and morbidity. BMC Public Health 2013; 13 (Suppl. 3): S19.

11. Black RE, Victora CG, Walker SP, et al. Maternal and child under-nutrition and over-weight in low-income and middle-income countries. Lancet 2013; 382: 427-51.

12. Alwelaie YA, Alsubaibani EA, Al-Harthy AM, Radwa RH, Al-Mobammady RG, AlMutairi AM. Breastfeeding knowledge and attitudes among Saudi women in central Saudi Arabia. Saudi Med J 2010; 31: 193-8

13. Mosalli R, Abd El-Azim A, Qutub M, Zagoot E, Janish M, Paes B. Perceived barriers to the implementation of a baby friendly initiative in Jeddah, Saudi Arabia. Saudi Med J 2012; 33: 895-900.

14. Federal MOH. National strategy for infant and young child feeding. $\mathrm{MOH}$, April 2004

15. Rani M. 5 reasons American women won't breastfeed. The Wall Street Journal. Retrieved from goo.gl/6CEbsC (2014, April 14).

16. Kliegman RM, Geme J. Nelson Textbook of Pediatrics. $17^{\text {th }}$ ed. Elsevier 2004; 157-65, 529-31.

17. American Academy of Pediatrics. Breastfeeding and the use of human milk. Pediatrics 2012; 129: 600-3.

18. Ayed A. Knowledge, attitude and practice regarding exclusive breastfeeding among mothers attending primary health care centers in Abha city. Int J Med Sci Public Health 2014; 3: 1355-63.

19. Essien NC, Samson-Akpan PE, Ndebbio TJ, John ME. Mothers' knowledge, attitudes, beliefs and practices concerning exclusive breastfeeding in Calabar, Nigeria. Africa J Nurs Midwifery 2009; 11: 65-75.

20. Wolde T, Diriba G, Wakjira A, Misganu G. Knowledge, attitude and practice amongst lactating mothers in Bedele town, southwestern Ethiopia: descriptive cross sectional study. Researcher 2014; 6: 91-7.

21. Oche M, Umer A, Ahmed H. Knowledge practice of exclusive breast feeding in kware,Nigeria: across sectional study involving women of child bearing age. Afr Health Sci 2011; 11: 518-23.

22. Madani KA, Al-Nowaisser AA, Khashoggi RH. Breast-feeding patterns in Saudi Arabia. Ecol Food Nutr 1994; 31: 239-45.

23. Al-Binalia AM. Breastfeeding knowledge, attitude and practice among school teachers in Abha female educational district, southwestern Saudi Arabia. Int Breastfeed J 2012; 7: 10.

24. Al-Binalib AM. Knowledge, attitude and practice of breast-feeding among female health care workers in tertiary care hospitals. Med J Cairo Univ 2012; 80: 159-64.

25. Al-Hreashy FA, Tamim HM, Al-Baz N, et al. Patterns of breastfeeding practice during the first 6 months of life in Saudi Arabia. Saudi Med J 2008; 29: 427-31.

26. Central statistical agency (Ethiopia) and ORC Macro 2006. Ethiopian demographic and health survey 2005.

27. Tadele N, Habta F, Akmel D, Deges E. Knowledge, attitude and practice towards exclusive breastfeeding among lactating mothers, Mizan Aman Town, Southwestern Ethiopia: descriptive cross sectional study. J Health Educ Res Develop 2015; 3: 3.

28. Gilani SA, Safdar M, Kousar CJR, Shahzadi C. The assessment of KAP of EBF among mothers: Lahore, Pakistan: Saudi J Med 2017; 2: $76-84$ 